$\begin{gathered}\text { Науковий вісник НлТУ України } \\ \text { Scientific Bulletin of UNFU } \\ \text { https://nv.nltu.edu.ua }\end{gathered}$
$\begin{gathered}\text { https://doi.org/10.15421/40290511 } \\ \text { Article received 21.05.2019 p. }\end{gathered}$
Article accepted 30.05.2019 p.
ISSN 2519-2477 (online)
УДк 630*[524.4+174.752+2(23)](477)

С. В. Портах, М. П. Горошко, В. В. Гаврилюк

Національний лісотехнічний університет Украйни, м. Львів, Украӥна

\title{
ПРОГНОЗУВАННЯ ДІАМЕТРА БЕЗ КОРИ НА РІЗНІЙ ВИСОТІ СТОВБУРІВ ДЕРЕВ ЯЛИЦІ БІЛОЇ В УКРАЇНСЬКИХ КАРПАТАХ
}

\begin{abstract}
Дослідження особливостей взаємозв'язку між діаметрами в корі та без кори на різних висотах стовбурів ялиці білої здійснено за результатами замірів 60 модельних дерев (27 для умов $\mathrm{C}_{3}$ та 33 для умов $\mathrm{D}_{3}$ ) у модальних ялицевих деревостанах Українських Карпат. Встановлено, що досліджувані типи лісорослинних умов (ТЛРУ) $\mathrm{C}_{3}$ та $\mathrm{D}_{3}$ не мають істотного впливу на значення товщини кори дерев ялиці. Регресійні залежності між діаметрами в корі та без кори встановлено способом порівняння біометричних показників восьми рівнянь, які запропонували різні автори. Розраховані на основі дев'яти біометричних показників середні ранги досліджуваних рівнянь показали, що найкраще взаємозв'язок між діаметрами в корі та без кори для стовбурів дерев ялиці описує рівняння, яке запропонував Crous (2009) (№ 4), а найгірші результати - рівняння № 6 (Meyer, 1946). Рівняння, що враховують висоту заміру діаметрів, загалом дали точніші результати, порівняно 3 іншими. Найбільші значення відхилень між фактичними та модельними значеннями діаметрів без кори спостережено у верхівковій частині стовбура (відносна висота - понад 0,8 ). Здійснено вирівнювання отриманих коефіцієнтів регресії для рівняння Сrous (2009) за способом найменших квадратів з використанням квадратичної функції. Середнє відхилення між фактичними та змодельованими діаметрами без кори становить 0,13 \%, що свідчить про адекватність підібраного рівняння.
\end{abstract}

Ключові слова: модельне дерево; біометричні показники; коефіцієнти регресії; ранг рівняння.

Вступ. На 2017 р. ялицеві ліси в Українських Карпатах за площею посідали друге місце серед хвойних (після ялини європейської) та четверте місце 3-поміж усіх порід (Portakh, 2019). Дослідження особливостей росту і розвитку ялицевих лісостанів $є$ невід'ємною частиною таксаційних досліджень регіону Українських Карпат (Golubetc, 1988; Goroshko, 1978; Hrynyk, 2011; Markiv \& Pitikin, 1990; Molotkova, 1965; Saban \& Kichura, 1974; Terelia, 2003; Tcurik, 1991; Shvidenko, 1980).

Обліковування ділової деревини здійснюється без кори, тому відомості про товщину кори (різницю діаметрів у корі та без кори) або iї частку в деревному стовбурі та можливість спрогнозувати ці величини 3 достатньою точністю вздовж деревного стовбура є важливими під час дослідження товарності та сортиментації запасу.

Сьогодні існує багато таксаційних приладів, зокрема дендрометрів різної конструкції, за допомогою яких можна виміряти діаметр стовбура в корі на різній висоті. На основі цих даних, знаючи для певної деревної породи залежності між діаметрами в корі та без кори, можна визначити об'єм дерева в корі та без кори, не зрубуючи його.

Товщина кори залежить від багатьох чинників. Найперше - від виду дерева та пов'язаних з цим генетичних особливостей стовбура та характеристик росту дерева (Anuchin, 1982; Li \& Weiskittel, 2011; Meyer, 1946; Thomas \& Bennett, 2014). 3 товщиною кори тісно корелюють такі таксаційні показники, як: вік дерева та залежні від нього діаметр на висоті грудей і загальна висота стовбура, а також відстань від основи стовбура до точки, на якій заміряється товщина кори.

Метою дослідження було визначення найадекватнішої функції для опису взаємозв'язку між діаметрами стовбура в корі та без кори для модальних ялицевих деревостанів Українських Карпат.

Матеріали та методи дослідження. Серед методик, які найчастіше використовували для отримання вихідних даних під час дослідження діаметра без кори, варто згадати такі:

- визначення діаметра без кори як різниці діаметра в корі і товщини кори, заміряної на кернах на різних висотах, отриманих за допомогою відповідних інструментів (віковий бурав, шведський кірний молоток (Swedish bark gauge), вирізання зразків за допомогою фрези та дриля);

- визначення діаметрів у корі та без кори під час вимірювання обводу стовбура за допомогою мірної стрічки до та після окорювання;

- вимірювання діаметрів у корі та без кори на стовбурових зрізах зі зрубаних модельних дерев, взятих на різній висоті від основи стовбура.

Кожен із цих способів має свої переваги і недоліки та їх обирає дослідником залежно від його можливос-

Інформація про авторів:

Портах Степан Володимирович, асистент, кафедра лісової таксації та лісовпорядкування. Email: portakh@nltu.edu.ua

Горошко Мирон Петрович, канд. с.-г. наук, професор, завідувач кафедри лісової таксації та лісовпорядкування.

Email: portakh@nltu.edu.ua

Гаврилюк Василь Васильович, інженер, кафедра лісової таксації та лісовпорядкування. Email: vasilgavriluk2017@gmail.com

Цитування за ДСту: Портах С. В., Горошко М. П., Гаврилюк В. В. Прогнозування діаметра без кори на різній висоті стовбурів дерев ялиці білої в Українських Карпатах. Науковий вісник НЛтУ України. 2019, т. 29, № 5. С. 56-59.

Citation APA: Portakh, S. V., Horoshko, M. P., \& Havryliuk, V. V. (2019). Predicting Under-Bark Diameter on Different Height of the tree Stems of White fir in the Ukrainian Carpathians. Scientific Bulletin of UNFU, 29(5), 56-59. https://doi.org/10.15421/40290511 
тей та поставлених цілей. Основною перевагою першої методики $\epsilon$ те, що для отримання даних нам не потрібно зрубувати дерево. Дві наступні методики потребують зрубування дослідних дерев, що значно збільшує час для здійснення дослідження. Остання методика $є$ найбільш трудо- та часозатратною, проте і обсяг отриманих дослідних даних також є найбільшим.

Дослідження взаємозв'язку між діаметрами в корі та без кори на різних висотах стовбура ми здійснювали за результатами замірів 60 модельних дерев (27 для умов $\mathrm{C}_{3}$ (вологий сугруд) та 33 для умов $\mathrm{D}_{3}$ (вологий груд). Спочатку залежності між діаметрами в корі та без кори на різних висотах стовбура встановлювали окремо для умов $\mathrm{C}_{3}$ та $\mathrm{D}_{3}$. За отриманими даними обчислили товщину кори на різній висоті стовбура для різних ТЛРУ (рис. 1).

Порівняння даних для різних ТЛРУ (див. рис. 1) показало, що значення товщини кори для умов $\mathrm{C}_{3}$ та $\mathrm{D}_{3} \mathrm{\epsilon}$ близькими для однакових діаметрів на різних висотах стовбура. Для порівняння вибіркових середніх значень товщини кори для різних типів лісорослинних умов ми використали непараметричний $\chi$-критерій Ван-дер-Вардена, оскільки його можна застосовувати за невідомих законів розподілу для вибірок з незв'язаними попарно варіантами (Horoshko, Myklush \& Khomiuk, 2004).

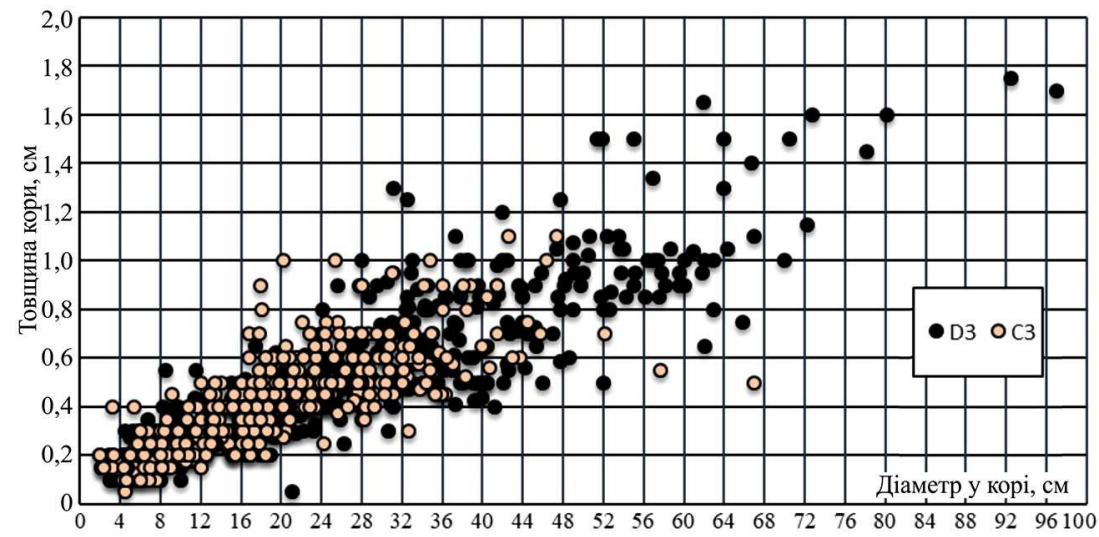

Рис. 1. Залежність товщини кори від діаметра в корі для різних ТЛРУ

Порівняння середніх значень товщини кори дало фактичне значення $\chi$-критерію 3,21 за критичного значення 5,59 (на $5 \%$ рівні істотності), що свідчить про неістотний вплив цих лісорослинних умов на відмінність у товщині кори. Отримані результати дають змогу нам застосовувати однакові коефіцієнти рівнянь залежності діаметрів у корі та без кори на різних висотах для умов $\mathrm{C}_{3}$ та $\mathrm{D}_{3}$. Кореляційний аналіз зв'язку між діаметрами в корі та без кори свідчить, що між цими величинами існує прямий, дуже тісний зв'язок (коефіцієнт кореляції становить 0,993), який за формою є прямолінійним (міра криволінійності дорівнюе 0,0002).

Для встановлення особливостей взаємозв'язку між діаметрами стовбура в корі та без кори на основі аналізу результатів робіт попередників ми відібрали вісім рівнянь, які характеризувалися найкращими статистичними показниками (Crous, Morris \& Khoza, 2009; Gordon, Lundgren \& Hay, 1999; Johnson \& Wood, 1987; Laasasenaho, Melkas \& Alden, 2005; Meyer, 1946; Miles \& Smith, 2009; Muhairwe, 1999; Murphy \& Cown, 2015; Thomas \& Bennett, 2014):

1) Dolph (1989):

2) Cao \& Pepper (1986)

$$
d_{6 . \kappa i}=k_{1}+k_{2} \cdot d_{6 . \kappa i},
$$

$$
d_{\text {б... } i}=d_{\text {6.K. }}\left(k_{1}+k_{2} \cdot \frac{h_{i}}{H}+k_{3}\left(\frac{h_{i}}{H}\right)^{2}+k_{4} \cdot H+k_{5} \cdot \frac{d_{\delta \kappa .1,3}}{d_{6 . \kappa .1,3}}\right),
$$

3) Johnson \& Wood (1987); Muhairve (2000):

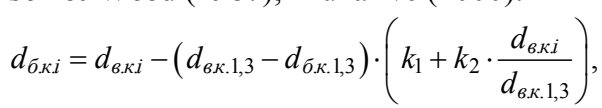

4) Crous (2009):

$d_{\text {б...i }}=d_{\text {6.K. }} \cdot\left(k_{1}+k_{2} \cdot \frac{h_{i}}{H}+k_{3}\left(\frac{h_{i}}{H}\right)^{2}+k_{4}\left(\frac{h_{i}}{H}\right)^{3}+k_{5}\left(\frac{h_{i}}{H}\right)^{4}+1\right)^{-1}$

5) Gordon (1999):

$$
d_{\text {б...i }}=d_{6 . \kappa . i} \cdot \sqrt{k_{1}+k_{2} \cdot \frac{l_{i}}{H}+k_{3} \cdot\left(\frac{l_{i}}{H}\right)^{2}},
$$

6) Meyer (1946):

$$
d_{\sigma . \kappa i}=d_{6 . \kappa i} \cdot \frac{\sum d_{\sigma . \kappa .}}{\sum d_{6 . \kappa .}}
$$

7) Miles (2009) (інтерпретоване рівняння Hilt, 1983):

$$
d_{\tilde{\sigma . \kappa .} .}=d_{6 . \kappa i} \cdot\left(k_{1}+k_{2} \cdot \frac{d_{6 \kappa . i}}{d_{6 . \kappa .1,3}}\right),
$$

8) Thomas \& Bennett (2014):

$$
d_{\delta . \kappa . i}=d_{B . K i} \cdot\left(1-2 k_{2}\right)-2 k_{1}-2 k_{3} \cdot H,
$$

де: $d_{6 \kappa . i}, d_{б \kappa . i}-$ діаметри в корі та без кори на $i$-й висоті, см; $d_{6 . \kappa .1,3}, d_{б . \kappa .1,3}-$ діаметри в корі та без кори на висоті 1,3 м, см; $h_{i}$ - висота, на якій заміряли діаметри в корі та без кори, м; $H$ - загальна висота стовбура, м; $l_{i}-$ відстань від верхівки стовбура до точки заміру діаметрів, $\mathrm{M} ; k_{1}, \ldots, k_{5}-$ коефіцієнти рівнянь.

Коефіцієнти рівнянь визначали за способом найменших квадратів з використанням програми Microsoft $E x$ cel 2016. Визначали найадекватніше рівняння на основі порівняння таких біометричних показників:

1) середня абсолютна похибка:

$$
C A \Pi_{y}=\frac{1}{N} \sum_{i=1}^{N}\left|d_{i y}-\hat{d}_{i y}\right|,
$$

2) середньоквадратична похибка:

$$
C K \Pi_{y}=\sqrt{\frac{1}{N-k} \sum_{i=1}^{N}\left(d_{i y}-\hat{d}_{i y}\right)^{2}},
$$

3) коефіцієнт детермінації:

$$
\kappa Д_{y}=1-\frac{\sum_{i=1}^{N}\left(d_{i y}-\hat{d}_{i y}\right)^{2}}{\sum_{i-1}^{N}\left(d_{i y}-\bar{d}\right)^{2}},
$$

4) корінь середньоквадратичної похибки: 


$$
K C K \Pi_{y}=\sqrt{\frac{1}{N} \sum_{i=1}^{N}\left(d_{i y}-\hat{d}_{i y}\right)^{2}},
$$

5) сума квадратів відхилень:

$$
C K B_{y}=\sum_{i=1}^{N}\left(d_{i y}-\hat{d}_{i y}\right)^{2},
$$

6) сума квадратів відносних відхилень:

$$
C K B B_{y}=\sum_{i=1}^{N}\left(\frac{d_{i y}-\hat{d}_{i y}}{d_{i y}}\right)^{2},
$$

7) відносна середньоквадратична похибка, \%:

$$
B C K \Pi_{y}=\frac{100}{N} \sum_{i=1}^{N}\left(\frac{d_{i y}-\hat{d}_{i y}}{d_{i y}}\right)^{2},
$$

8) коефіцієнт відхилення:

$$
K B_{y}=\frac{\sum_{i=1}^{N}\left(\hat{d}_{i y}-\hat{\bar{d}}\right)^{2}}{\sum_{i=1}^{N}\left(d_{i y}-\bar{d}\right)^{2}},
$$

9) середнє відхилення:

$$
C B_{y}=\frac{\sum_{i=1}^{N}\left|d_{i y}-\hat{d}_{i y}\right|}{\sum_{i=1}^{N} \hat{d}_{i y}} \cdot 100,
$$

де: $d_{i y}-$ фактичний діаметр без кори на $i$-й висоті $y$-го дерева, см; $\bar{d}$ - середній фактичний діаметр без кори, см; $\hat{d}_{i y}-$ змодельований діаметр без кори на $i$-й висоті $y$-го дерева, см; $\hat{\bar{d}}$ - середній змодельований діаметр без кори, см; $N$ - кількість замірів по висоті, шт.; $k-$ кількість коефіцієнтів регресії, шт.

Основні біометричні показники для різних рівнянь наведено в табл. 1.

За наближеністю до оптимального значення біометричних показників здійснювалося ранжування рівнянь від 1 до 8. Далі суму рангів для кожного рівняння ділили на кількість оцінкових біометричних показників (9) i визначали середній ранг рівняння. Аналіз отриманих результатів дає змогу зробити висновок, що найкращим для визначення діаметра без кори за діаметром у корі $\epsilon$ рівняння № 4 (Crous, 2009), за всіма біометричними показниками воно випереджає решту. На другому місці знаходиться рівняння № 2 (Сао \& Pepper, 1986), далі йде № 5 (Gordon, 1999). Найгірші результати показало рівняння № 6 (Meyer, 1946). Як бачимо, рівняння, що

\begin{tabular}{|c|c|c|c|c|c|c|c|c|c|}
\hline \multirow{2}{*}{$\begin{array}{c}\text { Біометричний } \\
\text { показник }\end{array}$} & \multirow{2}{*}{$\begin{array}{c}\text { Оптимальне } \\
\text { значення }\end{array}$} & \multicolumn{8}{|c|}{ Номер рівняння } \\
\hline & & 1 & 2 & 3 & 4 & 5 & 6 & 7 & 8 \\
\hline$C A \Pi_{v}$ & 0 & 0,18399 & 0,13448 & 0,14920 & 0,10873 & 0,13496 & 0,18573 & 0,15260 & 0,18015 \\
\hline$C K \Pi_{v}$ & Мінім. & 0,25411 & 0,19817 & 0,21452 & 0,16489 & 0,19815 & 0,25963 & 0,21572 & 0,25037 \\
\hline КД & 1 & 0,99966 & 0,99980 & 0,99976 & 0,99986 & 0,99980 & 0,99965 & 0,99976 & 0,99967 \\
\hline$K C K \Pi_{y}$ & Мінім. & 0,25382 & 0,19761 & 0,21416 & 0,16443 & 0,19782 & 0,25963 & 0,21548 & 0,24995 \\
\hline$C K B_{y}$ & 0 & 57,66 & 34,95 & 41,05 & 24,20 & 35,02 & 60,33 & 41,55 & 55,92 \\
\hline$C K B B_{y}$ & 0 & 0,45163 & 0,21007 & 0,25143 & 0,12447 & 0,21471 & 0,42569 & 0,36068 & 0,43079 \\
\hline$B C K \Pi_{y}$ & 0 & 0,05046 & 0,02347 & 0,02809 & 0,01391 & 0,02399 & 0,04756 & 0,04030 & 0,04813 \\
\hline$K B_{y}$ & 1 & 0,99191 & 0,99844 & 0,99837 & 0,99939 & 0,99842 & 0,99011 & 0,99632 & 0,99263 \\
\hline$C B_{y}$ & 0 & 0,78860 & 0,57707 & 0,64022 & 0,46666 & 0,57912 & 0,79716 & 0,65457 & 0,77228 \\
\hline \multicolumn{2}{|c|}{ Середній ранг рівняння } & 7,22 & 2,17 & 4,06 & 1,00 & 2,83 & 7,56 & 4,94 & 6,22 \\
\hline
\end{tabular}
враховують висоти, на яких заміряються діаметри, дають точніші результати. Недоліком цих рівнянь $є$ потреба додаткових замірів цих висот та загальної висоти стовбура дерева.

Табл. 1. Біометричні показники рівнянь залежності діаметрів у корі та без кори на різних висотах стовбура

Аналіз розподілу відхилень (\%) між фактичними та модельними значеннями діаметрів без кори, отриманих за різними рівняннями, показав, що найбільші їхні значення спостерігаємо у верхівковій частині стовбура (вище від 0,8 відносної висоти стовбура). Для вирівнювання отриманих коефіцієнтів рівняння № $4\left(k_{1}, \ldots, k_{5}\right)$ ми використали квадратичну функцію (поліном другого порядку) з визначенням параметрів цього рівняння $\left(b_{1}\right.$, $\left.b_{2}, b_{3}\right)$ за методом найменших квадратів (табл. 2).

Табл. 2. Параметри для визначення коефіціснтів регресії рівняння залежності діаметра в корі від діаметра без кори

\begin{tabular}{|c|c|c|c|c|c|}
\hline Параметри & \multicolumn{5}{|c|}{ Коефіціснти рівняння № 4 } \\
\cline { 2 - 6 } рівняння & $k_{1}$ & $k_{2}$ & $k_{3}$ & $k_{4}$ & $k_{5}$ \\
\hline$b_{1}$ & 0,07849 & $-0,15921$ & 0,18371 & 0,03040 & $-0,04800$ \\
\hline$b_{2}$ & $-0,00127$ & $-0,00073$ & 0,02581 & $-0,05248$ & 0,02961 \\
\hline$b_{3}$ & 0,00001 & 0,00009 & $-0,00077$ & 0,00157 & $-0,00107$ \\
\hline
\end{tabular}

Вирахувані за отриманими коефіцієнтами регресії значення діаметра без кори порівнювали з фактичними даними способом визначення відхилення у відсотках. Середнє значення цього відхилення становить $0,13 \%$. Розбіжності між фактичними та модельними значеннями без кори наочно можна побачити на рис. 2.

3 наведеного вище рисунка можна зробити висновок про відсутність значних відхилень між фактичними та модельними значеннями діаметра без кори, що свідчить про адекватність підібраного рівняння.

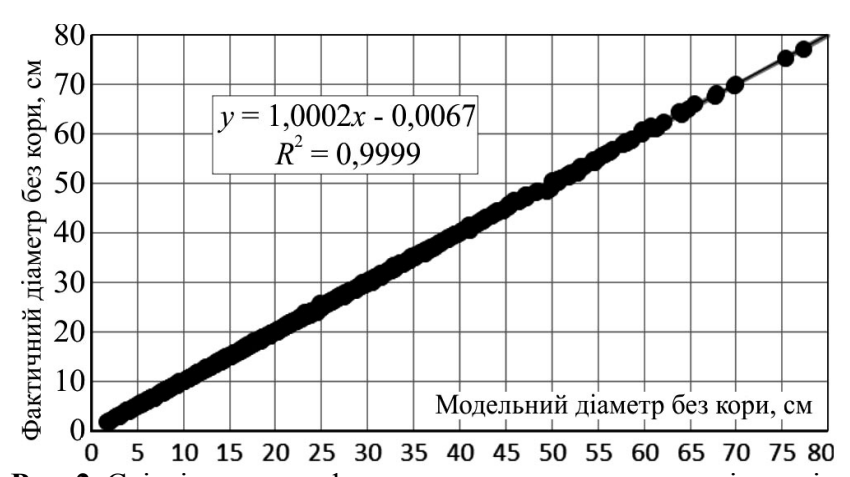

Рис. 2. Співвідношення фактичних та змодельованих діаметрів без кори

Висновки. Між діаметрами в корі та без кори стовбурів дерев ялиці білої існує тісний прямолінійний кореляційний зв'язок. Рівняння, що містять висоти заміру діаметрів та загальну висоту стовбура, характеризуються вищою точністю, порівняно з тими, що використовують тільки показники діаметрів у корі та без кори. Серед перших найкращі результати показало рівняння, запропонував Crous (2009) (№ 4), серед останніх - рівняння, що використав Johnson \& Wood (1987) (№ 3). Обчислені параметри для визначення коефіцієнтів регресії рівняння № 4 дають змогу з високою точністю під час сортиментації запасу визначати діаметри стовбурів ялиці білої без кори за відомого діаметра в корі, про що 
свідчать малі значення середнього відхилення між фактичними та змодельованими даними.

\section{Перелік використаних джерел}

Anuchin, N. P. (1982). Lesnaia taksatciia. (5th ed.). Moscow: Lesnaia prom-st, 552 p. [In Russian].

Cao, Q. V., \& Pepper, W. D. (1986). Predicting inside bark diameter for shortleaf loblolly and longleaf pines. Southern Journal of Applied Forestry, 10(4), 220-224.

Crous, J. W., Morris, A. R., \& Khoza, S. (2009). Effect of weeding and fertilisation on bark thickness and stem form of seven pine species on a low-elevation site at Usutu, Swaziland. Southern Forests. Journal of Forest Science, 71(3), 215-225. https://doi.org/10.2989/SF.2009.71.3.6.918

Golubetc, M. A. (1988). Pikhtovye lesa (formatciia Abieta). Ukrainskie Karpaty. Priroda, 86-91. Kyiv: Scientific thought. [In Russian].

Gordon, A. D., Lundgren, C., \& Hay, E. (1999). Composite taper equations to predict over- and under-bark diameter and volume of Eucalyptus pilularis, E. globoidea, and E. muelleriana in New Zealand. New Zealand Journal of Forestry Science, 29(2), 311-317.

Goroshko, M. P. (1978). Osobennosti stroeniia, rost i perspektivy iskusstvennykh pikhtarnikov Ukrainskikh Karpat. Abstract of Candidate Dissertation for Agricultural Sciences. Lviv, 26 p. [In Russian].

Horoshko, M. P., Myklush, S. I., \& Khomiuk, P. H. (2004). Biometriia. Lviv: Kamula, 236 p. [In Ukrainian].

Hrynyk, H. H. (2011). Forestry and assessment characteristics of silver-fir forests stands in Ukrainian Carpathians account relief features. Scientific Bulletin of UNFU, 21(13), 17-28. [In Ukrainian].

Johnson, T. S., \& Wood, G. B. (1987). Simple linear model reliably predicts bark thickness of radiata pine in the Australian capital territory. Forest Ecology \& Management, 22(3-4), 173-184.

Laasasenaho, J., Melkas, T., \& Alden, S. (2005). Modelling bark thickness of Picea abies with taper curves. Forest Ecology and Management, 206, 35-47. https://doi.org/10.1016/j.foreco.2004.10.058

Li, R., \& Weiskittel, A. R. (2011). Estimating and predicting bark thickness for seven conifer species in the Acadian Region of North America using a mixed-effects modeling approach: comparison of model forms and subsampling strategies. Eur. J. Forest Res., 130, 219-233. https://doi.org/10.1007/s10342-010-0423-y

Markiv, P. D., \& Pitikin, A. I. (1990). Produktivnost gornykh pikhtovykh lesov Karpat. Forestry, 12, 16-18. [In Russian].

Meyer, H. A. (1946). Bark Volume Determination in Trees. Journal of Forestry, 44(12), 1067-1070 https://doi.org/10.1093/jof/44.12.1067

Miles, P. D., \& Smith, W. B. (2009). Specific gravity and other properties of wood and bark for 156 tree species found in North America. US Dept. of Agriculture For Serv. Northern Exp. St. Research Note NRS-38, $35 \mathrm{p}$.

Molotkova, I. I. (1965). Stroenie, biologiia i sortimentnaia struktura estestvennykh pikhtovykh nasazhdenii Zakarpatia. Abstract of Candidate Dissertation for Agricultural Sciences (06.03.02 - Forest Management and Forest Taxation). Kharkiv, 23 p. [In Russian].

Muhairwe, C. K. (1999). Bark thickness equations for five commercial tree species in regrowth forests of Northern New South Wales. Australian Forestry, 63(1), 34-43. https://doi.org/10.1080/00049158.2000.10674811

Murphy, G., \& Cown, D. (2015). Within-tree, between-tree, and geospatial variation in estimated Pinus radiata bark volume and weight in New Zealand. New Zealand Journal of Forestry Science, 45(18), 1-7. https://doi.org/10.1186/s40490-015-0048-5

Portakh, S. V. (2019). Suchasnyi stan yalytsevykh lisiv Ukrainskykh Karpat. Lisivnycha osvita i nauka: stan, problemy ta perspektyvy rozvytku: zbirnyk materialiv, 169-174. Malyn: Vyd-vo MLTK. [In Ukrainian].

Saban, Ya. O., \& Kichura, V. P. (1974). Khid rostu i tovarna struktura pryrodnykh yalytsevykh derevostaniv. Pidvyshchennia efektyvnosti lisovykh pidpryiemstv, 37-46. Lviv: Kameniar. [In Ukrainian].

Shvidenko, A. I. (1980). Pikhtovye lesa Ukrainy. Lviv: Higher school, 192 p. [In Russian].

Tcurik, E. I. (1991). Taksatciia pikhtovykh molodniakov Karpat. Kyiv: Lybid, 101 p. [In Russian].

Terelia, I. P. (2003). Yalytsia bila u lisakh Ukrainskykh Karpat: stan, vidtvorennia ta hospodarske vykorystannia. Abstract of Candidate Dissertation for Agricultural Sciences. Lviv, 16 p. [In Ukrainian].

Thomas, R. E., \& Bennett, N. D. (2014). Estimating bark thickness of common Appalacian hardwoods, (pp. 283-294). US Department of Agriculture, Forest Service, Northern Research Station.

S. V. Portakh, M. P. Horoshko, V. V. Havryliuk Ukrainian National Forestry University, Lviv, Ukraine

\section{PREDICTING UNDER-BARK DIAMETER ON DIFFERENT HEIGHT OF THE TREE STEMS OF WHITE FIR IN THE UKRAINIAN CARPATHIANS}

The research of correlation between over- and under-bark diameter and other caliber parameters of tree stems was based on the field data obtained from the results of the measurements of 60 model trees $\left(27\right.$ in conditions $\mathrm{C}_{3}$ and 33 in conditions $\left.\mathrm{D}_{3}\right)$ in common fir stands of the Ukrainian Carpathians. The verification of the significance of the effect of the types of forest vegetation on the bark thickness was carried out using the non-parametric Van der Waerden's X-criterion, since it can be used under unknown distribution laws for samples with unconnected pairwise variants. It was defined that the studied types of forest vegetation $\left(\mathrm{C}_{3}\right.$ and $\left.\mathrm{D}_{3}\right)$ do not have a significant effect on the value of the bark thickness of the fir trees. Investigations of the regression relationships between the over- and under-bark diameters were performed by using the eight equations proposed by the different authors. The average ranks were calculated on the basis of nine biometric indicators for each of the experimental equations (from 1 to 8 , where the first rank received the equation with the best results, and the eighth - with the worst ones). The best results showed the equation proposed by Crous, 2009 (No. 4), and the worst - the equation No. 6 (Meyer, 1946). Among the experimental equations, more accurate results were given by those that took into account the height of the diameters measurement. It was found that the greatest deviations between the actual and model values of under-bark diameters were observed in the upper part of the stems (values of the relative height were more than 0.8 ). The modeling of the obtained regression coefficients for the equation No. 4 was provided by the least squares method using second-degree polynomial equation. The low average deviation between actual and predicted under-bark diameters $(0.13 \%)$ indicates the adequacy of the selected equation.

Keywords: model tree; biometric indicators; coefficients of regression; rank of equation. 